\title{
Utilization of personal protective equipment and associated factors among textile factory workers at Hawassa Town, Southern Ethiopia
}

\author{
Sebsibe Tadesse ${ }^{1 *}$, Temesgen Kelaye $^{2}$ and Yalemzewod Assefa ${ }^{1}$
}

\begin{abstract}
Background: Use of personal protective equipment is one of the important measures to safeguard workers from exposure to occupational hazards, especially in developing countries. However, there is a dearth of studies describing personal protective equipment utilization in Ethiopia. The present study has determined the magnitude of personal protective equipment utilization and identified associated factors among textile factory workers at Hawassa Town, southern Ethiopia.

Methods: An institution-based cross-sectional study was conducted among textile factory workers at Hawassa Town, southern Ethiopia from January to March 2014. Stratified sampling followed by simple random sampling techniques was used to select the total of 660 study participants. A pre-tested and structured questionnaire was used to collect data. Multivariate analyses were employed to see the effect of explanatory variables on dependent variable.

Results: The magnitude of personal protective equipment utilization was $82.4 \%$. Service duration of $>10$ years [AOR: $0.23,95 \% \mathrm{Cl}:(0.09,0.58)]$, availability of personal protective equipments [AOR: 21.73, $95 \%$ Cl: $(8.62,54.79)]$, shift work [AOR: $2.28,95 \%$ Cl: $(1.12,4.66)]$, alcohol drinking [AOR: $0.26,95 \%$ Cl: $(0.10,0.66)]$, and cigarette smoking [AOR: $0.20,95 \% \mathrm{Cl}:(0.05,0.78)]$ were factors significantly associated with use of personal protective equipment.

Conclusion: In this study a relatively higher personal protective equipment utilization rate was reported compared to other studies in developing countries. However, this does not mean that there will be no need for further strengthening the safety programs as there are significant proportion of the workers still does not use all the necessary personal protective equipment during work. Interventions to promote use personal protective equipment should focus on areas, such as service duration, availability of protective equipment, presence of shift work, and control of substance abuse.
\end{abstract}

Keywords: Hazard control, Personal protective equipment, Safety, Textile factory, Workers

\section{Background}

The International Labour Organization has estimated that over 2 million people die every year from workrelated accidents and diseases, and over 300 million non-fatal accidents are recorded each year [1]. This translates into more than 6000 deaths and over 800,000

* Correspondence: sbsbtadesse90@gmail.com

${ }^{1}$ Institute of Public Health, The University of Gondar, Gondar, Ethiopia

Full list of author information is available at the end of the article non-fatal accidents every day. As a result of these, there is an estimated economic loss of more than $\$ 1.25$ trillion each year, which is equivalent to $4.0 \%$ of the world's Gross Domestic Product. This loss is 4 times higher for developing countries than that of industrialized countries [2,3]. In many low and middle income countries, such as Ethiopia statistics on occupational accidents and injuries are limited. In cases where such information is available it is largely impaired by 
underreporting. Considering the differences between countries, it is reasonable to agree that occupational deaths and injuries take a heavy toll among the poor and least protected.

Textile industry is one of labor intensive production and most technologically complex of all industries, and is a place of work where workers are exposed to different safety hazards, like cotton dust, excessive noise, accidents and diseases [4-7]. As result of this, workers, employers and government lost direct and indirect costs related to workplace injuries and illnesses [8]. The direct costs for employers include compensation and treatment costs that has to be paid to the disabled workers, and while the indirect costs include production disturbance costs, lost time of injured worker, time lost by supervisors or executive to follow the injured worker, training costs for new workers. The direct costs for workers include pain and suffering from the injury or illness, loss of income, loss of a job and health-care costs, and while the indirect costs include time lost by family members to care the disabled worker and utmost economic shock and social chaos $[9,10]$.

Use of personal protective equipment (PPE) is one of the important measures to safeguard workers from exposure to occupational hazards, especially in developing countries where conventional occupational safety control principles remain a challenge to implement [11-13]. Workers use of PPE is affected by socio-demographic, behavioral and work environment factors [14]. In textile factory they use different protective devices at different production sections. For example, they need to wear respirator, gloves, goggle, boot shoes, overall, ear plugs and mask at spinning section, and while reflector and helmet are worn in addition at engineering section.

Policies or measures for delivering health and safety services to factory workers are limited in Ethiopia. This not only limits their access to information and training opportunities but also places the workers at a greater risk to occupational injuries and diseases. Furthermore, literatures show that factory workers lack the knowledge on proper use of protective measures and are least aware of health effects emanating from the activities and materials in their work environments $[13,15,16]$.

There is a dearth of studies describing PPE utilization among textile factory workers in most of Subsaharan African countries, like Ethiopia. This paper presents the findings of a study which investigated PPE utilization and associated factors among textile factory workers in southern Ethiopia, a low-income country in East Africa. This study addresses a critical gap in understanding PPE utilization in Ethiopia and contributes to the growing workplace safety research in low-income countries. Such studies may also help in developing evidence-based intervention strategies targeted at promoting workers safety and health.

\section{Methods \\ Study design, area and period, and source population}

An institution-based cross-sectional study was conducted to assess the magnitude of PPE utilization and associated factors among textile factory workers at Hawassa Town, southern Ethiopia, from January to March 2014. The town is located at $275 \mathrm{~km}$ South of Addis Ababa, the capital city of Ethiopia. During the investigation, there are about 1370 workers in the factory. Of whom, $65.0 \%$ are permanent, $32.3 \%$ temporary, and $2.7 \%$ daily workers [17].

\section{Participants and data collection}

All textile factory workers who directly involved in the process of production at spinning, weaving, finishing, engineering, and garmenting departments were included in the study until the required sample size was obtained. Workers who were absent from work due to reasons other than work-related injuries during the time of data collection were excluded from the study. A pre-tested and structured interview questionnaire was used to collect the data. The questionnaire contained detail information on socio-demographic, behavioral and environmental factors, and utilization of PPE. Except age, all the factors were measured using a categorical scale of measurement.

\section{Sample size calculation}

Epi info version 7 was used to determine the sample size required for this study by taking 1370 total population, $49.3 \%$ expected proportion of sickness absenteeism, $3 \%$ confidence limit, and $95 \%$ confidence level. By adding $10 \%$ non-response rate, the total sample size was 660 .

\section{Sampling procedure}

Stratified sampling followed by simple random sampling techniques was used to select the study participants. That is, the manufacturing units were stratified into five departments: spinning, weaving, finishing, engineering, and garment department. Then, the total of 660 samples was proportionally allocated to each department. The participants were drawn from the factory's list of workers using simple random sampling.

\section{Data analyses}

The training of data collectors and supervisors emphasized issues such as data collection instrument, field methods, inclusion-exclusion criteria, and record keeping. The principal investigator and supervisors coordinated the interview process, spot-checked and reviewed the completed questionnaire on a daily basis to ensure 
the completeness and consistency of the data collected. The interview questionnaire was pre-tested on 20 workers who work in a factory nearly similar to Hawassa Textile Factory in order to identify potential problem areas, unanticipated interpretations, and cultural objections to any of the questions. Based on the pre-test results the questionnaire was adjusted contextually.

Data entered and cleaned using Epi info version 7 statistical software were analyzed on SPSS version 16. Frequency distribution, mean, standard deviation, and percentage, were used for descriptive analyses. All independent variables were fitted separately into bivariate logistic regression model to evaluate the degree of association with utilization of PPE. Then, variables with a p-value $<0.20$ were exported to multivariate logistic regression model to control confounders. The odds ratio (OR) with a $95 \%$ confidence interval (CI) was used to test the statistical significance of variables. The crude OR was used to present the bivariate model outputs while the adjusted OR to the multivariate outputs.

\section{Operational definitions Utilization of PPE}

Use of all the necessary worker-specialized clothing or equipment by workers for protection against health and safety hazards in the workplace [18]. Workers were classified as those who used PPE when they were observed wearing of all the PPE that were necessary to be worn during work in a particular working section. The necessarily worn PPE were: 1) a respirator, gloves, eye protector, boot shoes, overall, ear plugs and mask at spinning section, 2) respirator, gloves, eye protector, boot shoes, ear plugs and overall at weaving section, 3) respirator, gloves, mask, ear plugs, boot shoes and overall at finishing section, 4) respirator, gloves, boot shoes, eye protector, overall, reflector, mask and helmet at engineering section, and 5) gloves, boot shoes, mask and overall at garmenting section.

\section{Worker}

A person who is directly involved in the process of production and has an employment relationship with an employer [19].

\section{Marital status}

Workers are classified as married and single based on their risk difference to unsafe acts.

\section{Ethical considerations}

The study protocol was reviewed and approved by the Institutional Review Board of the University of Gondar via the Institute of Public Health. Permission was obtained from Hawassa Textile Factory Administrative Office prior to data collection. Study participants were interviewed after informed written consent was obtained. They were also informed that their participation was voluntary and that they could withdraw from the interview at any time without consequences. The participants were assured that their responses would be treated confidentially through the use of strict coding measures. Finally, safety education was given to workers who reported not utilizing the necessary PPE.

\section{Results}

\section{Socio-demographic characteristics}

A total of 660 workers who directly involved in the process of production participated in the study which makes the response rate $100 \%$. Of whom $80.8 \%$ were males and $19.2 \%$ females. The mean age with a standard deviation of the workers was $32.9 \pm 9.3$. More than twothirds, $68.8 \%$, of them belonged to the age group of 18-39 years. The majority, $60.5 \%$, attended secondary and above education. About half, $47.0 \%$, served for more than 10 years in the factory. The majority, $58.0 \%$, of the workers were married. Nearly twothirds, $63.3 \%$, had a monthly income of less than or equal to Birr 1500 (Table 1).

Table 1 Socio-demographic characteristics of textile factory workers at Hawassa Town, southern Ethiopia, 2014

\begin{tabular}{|c|c|c|}
\hline Variables & Number & Percent \\
\hline \multicolumn{3}{|l|}{ Sex } \\
\hline Male & 533 & 80.8 \\
\hline Female & 127 & 19.2 \\
\hline \multicolumn{3}{|l|}{ Age (in years) } \\
\hline $18-25$ & 200 & 30.3 \\
\hline $26-39$ & 254 & 38.5 \\
\hline$>39$ & 206 & 31.2 \\
\hline \multicolumn{3}{|l|}{ Educational status } \\
\hline Illiterate & 17 & 2.5 \\
\hline Primary & 244 & 37.0 \\
\hline Secondary & 203 & 30.8 \\
\hline Above secondary & 196 & 29.7 \\
\hline \multicolumn{3}{|c|}{ Service duration (in years) } \\
\hline $1-10$ & 350 & 53.0 \\
\hline$>10$ & 310 & 47.0 \\
\hline \multicolumn{3}{|l|}{ Marital status } \\
\hline Married & 383 & 58.0 \\
\hline Single & 277 & 42.0 \\
\hline \multicolumn{3}{|c|}{ Monthly income (in Birr) } \\
\hline $1-1000$ & 243 & 36.8 \\
\hline $1001-1500$ & 241 & 36.5 \\
\hline$>1500$ & 176 & 26.7 \\
\hline
\end{tabular}


Behavioral characteristics and environmental conditions The majority, 80.3, 84.1 and $85.9 \%$, of the workers reported that they did not drink alcohol, chew khat and smoke cigarette, respectively. Three-fourths, $74.5 \%$, stated that they were satisfied with their job. The majority, 98.6, 93.6 and $62.9 \%$, informed that they used work guidelines, received safety orientation and attended safety training, respectively. Nearly two-thirds, $61.5 \%$, complained that there was no safety supervision during their work. Eighty five percent of the workers reported that there was a work shift in the factory. Nearly half, $47.0 \%$, stated that there was no work rotation. Poor conditions of ventilation and light in the working rooms were testified by 72.3 and $48.9 \%$ of the workers, respectively (Table 2).

\section{Magnitude of PPE utilization}

Out of 660 workers $82.4 \%$ were observed wearing of all the necessary PPE during work at the time of interview. Of whom $82.0 \%$ were males and $18.0 \%$ females. The majority, $68.6 \%$, of them belonged to the age group of 18 to 39 years. Fifty eight percent were married.

The magnitude of PPE utilization was $73.0 \%$ spinning section, $76.0 \%$ weaving section, $87.6 \%$ finishing section, $87.3 \%$ engineering section, and $88.2 \%$ garmenting section (Table 3).

More than $17.0 \%$ of the workers reported that they did not use all the necessary PPE during work. The reasons for not using PPE were for $43.0 \%$ lack of PPE, for $20.0 \%$ lack of practice, for $20 \%$ uncomfortable to use, and for $17.0 \%$ lack of safety education.

\section{Factors associated with PPE utilization}

Table 4 presents factors which remained statistically significant in the bivariate and multivariate logistic regression analyses. In this study, the independent predictors of PPE utilization on the multivariate analysis include service duration of $>10$ years [AOR: $0.23,95 \% \mathrm{CI}$ : $(0.09$, 0.58)], availability of PPE [AOR: 21.73, $95 \% \mathrm{CI}$ : (8.62, 54.79)], shift work [AOR: $2.28,95 \%$ CI: $(1.12,4.66)]$, alcohol drinking [AOR: 0.26, $95 \%$ CI: $(0.10,0.66)]$, and cigarette smoking [AOR: $0.20,95 \%$ CI: $(0.05,0.78)$ ], (Table 4).

\section{Discussion}

In this study, the magnitude of PPE utilization among textile factory workers was $82.4 \%$. This finding is by far higher than that of studies from Asia (12.0-49.4 \%) $[14,20]$ and Africa $(16.7-75.3 \%)[12,13,15,18,21]$. The difference could be due to methodological differences, like study population and methods of data collection, and workplace conditions, like employees' level of awareness on hazard control and disease prevention and accessibility to safety services. However,
Table 2 Behavioral characteristics and environmental conditions of workers at Hawassa Textile Factory, southern Ethiopia, 2014

\begin{tabular}{|c|c|c|}
\hline Variables & Number & Percent \\
\hline \multicolumn{3}{|c|}{ Drink alcohol } \\
\hline Yes & 130 & 19.7 \\
\hline No & 530 & 80.3 \\
\hline \multicolumn{3}{|c|}{ Chew khat } \\
\hline Yes & 105 & 15.9 \\
\hline No & 555 & 84.1 \\
\hline \multicolumn{3}{|c|}{ Smoke cigarette } \\
\hline Yes & 93 & 14.1 \\
\hline No & 567 & 85.9 \\
\hline \multicolumn{3}{|c|}{ Satisfied with job } \\
\hline Yes & 492 & 74.5 \\
\hline No & 168 & 25.5 \\
\hline \multicolumn{3}{|c|}{ Used work guideline } \\
\hline Yes & 651 & 98.6 \\
\hline No & 9 & 1.4 \\
\hline \multicolumn{3}{|c|}{ Attended safety training } \\
\hline Yes & 415 & 62.9 \\
\hline No & 245 & 37.1 \\
\hline \multicolumn{3}{|c|}{ Orientation given } \\
\hline Yes & 618 & 93.6 \\
\hline No & 42 & 6.4 \\
\hline \multicolumn{3}{|c|}{ Safety supervision } \\
\hline Yes & 254 & 38.5 \\
\hline No & 406 & 61.5 \\
\hline \multicolumn{3}{|c|}{ Work shift } \\
\hline Yes & 562 & 85.2 \\
\hline No & 98 & 14.8 \\
\hline \multicolumn{3}{|c|}{ Work rotation } \\
\hline Yes & 350 & 53.0 \\
\hline No & 310 & 47.0 \\
\hline \multicolumn{3}{|c|}{ Ventilation } \\
\hline Good & 183 & 27.7 \\
\hline Poor & 477 & 72.3 \\
\hline \multicolumn{3}{|l|}{ Light } \\
\hline Good & 337 & 51.1 \\
\hline Poor & 323 & 48.9 \\
\hline
\end{tabular}

this does not mean that there will be no need for further strengthening the safety programs as there are significant proportion of the workers still does not use all the necessary PPE during work. The interventions should consider designing and provision of PPE, and regular safety education.

One important finding of this study was the identification of independent predictors influencing PPE utilization. 
Table 3 Magnitude of PPE utilization by working section among textile factory workers in Hawassa Town, southern Ethiopia, 2014

\begin{tabular}{lll}
\hline Working section & Number & Percent \\
\hline Spinning section & 199 & 73.0 \\
Used & 73 & 27.0 \\
Not used & 109 & \\
Weaving section & 34 & 76.0 \\
Used & & 24.0 \\
Not used & 65 & 87.6 \\
Finishing section & 9 & 12.4 \\
Used & & \\
$\quad$ Not used & 57 & 87.3 \\
Engineering section & 8 & 12.7 \\
Used & & \\
Not used & 94 & 88.2 \\
Garment section & 12 & 11.8 \\
Used & & \\
Not used &
\end{tabular}

It was found that the odds of PPE utilization among workers who served for greater than 10 years were 0.77 times less when compared to those who served for less than or equal to 10 years. The possible explanation for this may be that those who served for longer period could be accustomed to the work environment and developed false consciousness of safety which might drive them not to

Table 4 Factors associated with associated with PPE utilization among textile factory workers in Hawassa Town, southern Ethiopia, 2014

\begin{tabular}{|c|c|c|c|c|}
\hline \multirow[t]{2}{*}{ Variables } & \multicolumn{2}{|c|}{ Utilized PPE } & \multirow{2}{*}{$\begin{array}{l}\text { Crude OR } \\
(95 \% \mathrm{Cl})\end{array}$} & \multirow{2}{*}{$\begin{array}{l}\text { Adjusted OR } \\
(95 \% \mathrm{Cl})\end{array}$} \\
\hline & Yes & No & & \\
\hline \multicolumn{5}{|c|}{ Service duration (in year) } \\
\hline $1-10$ & 272 & 78 & 1.0 & 1.0 \\
\hline$>10$ & 272 & 38 & $2.05(1.35,3.13)$ & $0.23(0.09,0.58)$ \\
\hline \multicolumn{5}{|c|}{ PPE available } \\
\hline Yes & 531 & 62 & $0.03(0.02,0.05)$ & $21.73(8.62,54.79)$ \\
\hline No & 13 & 54 & 1.0 & 1.0 \\
\hline \multicolumn{5}{|l|}{ Shift work } \\
\hline Yes & 475 & 87 & $0.44(0.27,0.71)$ & $2.28(1.12,4.66)$ \\
\hline No & 69 & 29 & 1.0 & 1.0 \\
\hline \multicolumn{5}{|c|}{ Drink alcohol } \\
\hline Yes & 106 & 24 & $1.08(0.66,1.77)$ & $0.26(0.10,0.66)$ \\
\hline No & 438 & 92 & 1.0 & 1.0 \\
\hline \multicolumn{5}{|c|}{ Smoke cigarette } \\
\hline Yes & 86 & 7 & $0.34(0.15,0.76)$ & $0.20(0.05,0.78)$ \\
\hline No & 458 & 109 & 1.0 & 1.0 \\
\hline
\end{tabular}

comply with safety precautions including proper use of PPE. Thus, giving attention for this segment of workers may contribute for safety improvement.

Like in previous studies $[16,18]$, availability of PPE was found to be strong independent predictor of PPE utilization in this study. Cognizant of this fact, safety administration programs should consider availing of all the necessary PPE on regular bases to promote health and safety in the workplace.

In this study the odds of PPE utilization among workers who worked in shift were about two times high when compared to those who did not. The reason behind this could be that shift work encourages workers towards PPE utilization by providing adequate time to think for and communicate about their safety. This signifies that there is a need for revising of work schedule to promote use of PPE in the factory.

Cigarette smoking and alcohol drinking also showed significance association with PPE utilization. The odds of PPE utilization among cigarette smokers and alcoholists were 0.80 and 0.74 times less, respectively when compared to their counter parts. This might be due to the fact that smoking and drinking are proxy indicators of a certain degree of risk tolerance. A high blood level of such substances during work will endanger both safety and efficiency, and be the cause of increased likelihood of mistakes, poor decision making, and errors in judgment. As the result of this fact, the factory's safety policy should consider control of substance abuse at workplace.

Social desirability bias is a potential limitation in selfreported studies like this one, in that workers might report socially acceptable responses than their actual day to day practice. As this is a cross-sectional study, the limitations that come with this type of design need to be taken into consideration when interpreting the findings.

\section{Conclusion}

In this study a relatively higher PPE utilization rate was observed compared to other studies in developing countries. However, this does not mean that there will be no need for further strengthening the safety programs as there are significant proportion of the workers still does not use all the necessary PPE during work. Interventions to promote PPE utilization should focus on areas, such as service duration, availability of PPE, presence of shift work, and control of substance abuse.

Competing interests

The authors declare that they have no competing interest.

Authors' contribution

Author 1. ST: Involved in write up of the research proposal, the data analyses, and wrote the manuscript, Author 2. TK: Involved in write up of the research proposal, the data analyses, and wrote the manuscript, Author 3. YA: Involved in write up of the research proposal. All authors read and approved the final manuscript. 


\section{Acknowledgments}

The authors wish to thank the Southern Nations Nationalities and Peoples Regional State Bureau of Labor and Social Affairs for logistic and administrative support, and data collectors for their support in making this study possible. They also extend their deepest gratitude to the study participants.

\section{Author details}

'Institute of Public Health, The University of Gondar, Gondar, Ethiopia.

${ }^{2}$ Southern Nations Nationalities and People's Regional State Health Bureau, Hawassa, Ethiopia.

Received: 12 August 2015 Accepted: 15 February 2016

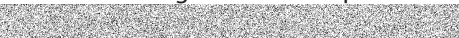

\section{References}

1. International Labour Organization. Safety and Health at Work; 2015. [Accessed at: 25/09/2015]. [Available from: http://ilo.org/global/topics/safetyand-health-at-work/lang-en/index.htm.]

2. International Labor Organization.Workplace health promotion;2014. [Accessed at: 1/15/2014]

3. International Labor Organization. World Day for Safety and Health at Work; 2013. [Accessed at: 1/15/2014].

4. Conn R, Barclay L. Health education in the workplace. AAOHN J. 2008;2(28):407-12.

5. Gawenda D. Occupational Health Nursing Care Guidelines. Springer Publishing Company, Boston 2008; 2(2):17-30.

6. Danton S. Prevention of Injury and Disease in occupational Health Nursing Practice, Harris CJ 2009; second edition, 48-75.

7. Sewefy A. Health hazard and safety. J Egypt Med Assoc. 2009;51(3):757.

8. Health and Safety Executive. Costs to Britain of workplace fatalities and self reported injuries and ill health; 2010/2011: 5-36.

9. Aghera N. Occupational health and safety with special reference to textile industry research scholar. Singhania university, Acheri Bari-Jhunjhunu 2013:2(3):2277-8160

10. Hildegunn K. The global textile and clothing industry post the agreement on textiles and clothing. World Trade Organization Geneva, Switzerland 2007; 2(3):6

11. Malik N, Mean AA, Pasha TS, Akhtar S, Ali T. Role of hazard control measures in occupational health and safety in the textile industry of Pakistan. Pak J Agri Sci. 2010;47(1):72-6.

12. Kamal A, Sayed M, Massoud A. Usage of personal protective devices among Egyptian industrial workers. Am J Ind Med. 2007;13(6):706-16.

13. Akintayo WL. Knowledge, attitude and practice on the use of personal protective equipment by traditional resist Fabrics workers in Abeokuta Nigeria. Kuwait Rev Chapter Arabian J Bus Manag Rev. 2013;2(7):31-3.

14. Jaiswal A. Case Control study among carpet thread factory workers in Uttar Pradesh, India: Occupational injury and its deteriorating factors. Global J Human Soc Sci History and Anthr 2012;12:22-30.

15. Motbainor A, Kumie A, Melkamu Y. Assessment of knowledge and practice on safety information among factory workers Addis Ababa, Ethiopia. Addis Ababa University; 2007.

16. Ahmad I, Qadir S, Muhammad, Yasir M, Irfanullah M, Khan MA, Aslam, SZ, Alam J, Iqbal J, Sikandar I, Waqas M. Knowledge, attitude and practice related to occupational health and safety among textile mills workers in Dera Ismail Khan. Gomal J Med Sci 2012;10 222-226.

17. Southern Nations Nationalities and Peoples Regional State. Hawassa textile factory manpower summary data. Hawassa: Hawassa Textile Factory; 2013.

18. Zungu L, Gabe SG. A survey of work, health and safety conditions in smallscale garment enterprises in Gaborone, Botswana. Occup Health Southern Africa 2011:17:13-19.

19. Ministry of Labor and Social Affairs. Labor proclamation No. 377/2003. Addis Ababa: Labor and Social Affairs; 2004

20. Parimalam P, Kamalamma N, Kumar A. Knowledge, attitude and practices related to occupational health problems among garment workers in Tamil Nadu, India. J Occup Health. 2007:49(6):528-34.

21. Aderaw Z, Engedaw D, Tadesse T. Determinants of occupational injury: a case control study among textile factory workers in Amhara Regional State, Ethiopia. J Trop Med. 2011;2011:1-8

\section{Submit your next manuscript to BioMed Central and we will help you at every step:}

- We accept pre-submission inquiries

- Our selector tool helps you to find the most relevant journal

- We provide round the clock customer support

- Convenient online submission

- Thorough peer review

- Inclusion in PubMed and all major indexing services

- Maximum visibility for your research

Submit your manuscript at www.biomedcentral.com/submit 